\title{
Synthesis, Characterization and Conductance Properties of Cobalt Chloride Doped Polyvinyl Alcohol / Polythiophene (PVA-Co-Pth) Nanocomposite Films
}

\author{
Anand Patil ${ }^{1} \cdot$ Nirdosh Patil ${ }^{2}$ \\ ${ }^{1}$ Department of Chemistry, P D A College of Engineering, Aiwan-E- shahi Road, Kalaburagi, Karnataka-585 102, India. \\ ${ }^{2}$ Department of Chemistry, Sharnbasva University, Vidya Nagar, Kalaburagi, Karanataka-585 103, India.
}

\begin{abstract}
Polyvinylalcohol-Co-polythiophene (PVA-Co-PTh) composite polymer films were produced by chemical polymerization. Cobalt chloride $\mathrm{CoCl}_{2} 6 \mathrm{H}_{2} \mathrm{O}$ was applied on various levels as doping $(0.2$, $0.4,0.6$ and $0.8 \mathrm{~g}$ ). The produced films were characterized by TEM (transmission electron microscopy), UV-Visible spectroscopy, IR (Infra red spectroscopy), SEM (scanning electron microscope), XRD (Xray diffraction), d.c electrical conductivity, and dielectric constant measurements. The optical properties of all investigated films were analyzed, when the optical absorption of the prepared films reduces with raising the amount of $\mathrm{CoCl}_{2} \cdot 6 \mathrm{H}_{2} \mathrm{O}$ in UV $(200-400 \mathrm{~nm})$ \& VIS (500-700nm) regions. It is evident from the XRD patterns of the PVA-Co-PTh samples that the intensity of the peaks of diffraction rises with the rise in cobalt chloride content owing to the semi crystalline of the resulting Co (II) doped PVA/PTh compositions. These findings are comparable with morphological variations seen in the PVA-Co-PTh samples, as per the TEM and SEM analysis. The increase in conductivity with increase in Co (II) concentration up to $0.8 \mathrm{~g}$ of $\mathrm{CoCl}_{2} 6 \mathrm{H}_{2} \mathrm{O}$ has been observed in PVA-Co-PPy composites and the dielectric constant tends to increase with the increment infrequency as well as with enhancement in Co (II) composition.

(c) 2022 JMSSE - INSCIENCEIN. All rights reserved
\end{abstract}

ARTICLE HISTORY

Received 26-06-2021

Revised 01-12-2021

Accepted 03-12-2021

Published 12-01-2022

\section{KEYWORDS}

PVA-Co-Pth

Nanocomposite

$\mathrm{X}$-ray diffraction

SEM, TEM

Dielectric constant

\section{Introduction}

Naturally, nanotechnology is very wide, covering the fields such as micro-fabrication, semiconductor physics, molecular biology, surface science, etc. Synthetic polymers are human-made polymers, they are often found in a range of consumer items like super glue, money, and so on.[1]. Polyvinyl alcohol is odorless and white (colorless). Polyvinyl alcohol has good film-forming, adhesive and emulsifying properties [2]. PVA has a melting point at 180 to $190^{\circ} \mathrm{C}$ (356 to $374^{\circ} \mathrm{F}$ ) and $230{ }^{\circ} \mathrm{C}$ for the partially hydrolyzed as well as fully hydrolyzed grades. It decomposes quickly at $200{ }^{\circ} \mathrm{C}$ at high temperatures it might experience pyrolysis. PVA is almost incompressible. Polythiophenes become "organic metals" electrically conductive after partial oxidization. Thiophene was found to be a benzene contaminant. Thiophene was the novel heterocyclic compound [3]. Polythiophene was frequently utilized in ecologically as well as thermally conjugated polymers materialslike transistors, solar cells, polymer electronic interconnects, DNA detection, molecular devices, light-emitting diodes, and displays, photovoltaic devices, optical and chemical sensors.

In recent decades, because of its better flexibility, stability and cost-efficiency, the usage of conductive polymer composites has been taken into account for the manufacture of display and sensing equipments [4] Comprehensive investigations on gas sensing characteristics of PANI composites [5,6] and polypyrrole (PPy) composites were noted for different oxidation and gas reduction $[7,8]$. But, to resolve their solubility constraints and electrochemical properties of the conducting PANI composites are mostly owing to the polymerization methods, non-homogeneous composite formation, as well as doping dedoping properties of the conducting polymers, further more to increased process ability as well as mechanical properties, there is required to produce a real composite of conducting polymers with fundamental properties of the conductive polymers. The enhancement of these properties could be obtained through the forming of pyrrole copolymers or the forming composites PPY or through mixing with commercially available inorganic materials or polymers that provide better optically as well as mechanical characteristics, stability, and processing capacity $[9,10]$ thus polypyrrole blends with an isolating polymer has good mechanical characteristics [11,12]. Electrochemical or chemical polymerization may be used to create polymer composites. Substantial influence on the electrical and optical characteristics of PVA polymers, like transition metal salts $[13,14,15]$. In this work, the host material PVA is integrated into the conductive composite polymer consisting of "polythiophene" (PTh). In this study, the PVA: "polyvinyl alcohol" was utilized as an isolating polymer and blended with PTh by applying chemical polymerization to enhance the PTh properties. To examine the effect of doping compositions on the structural, optical as well as electrical characteristics of the composite polymer, the doping concentration, particularly hydrous cobalt chloride, was changed.

\section{Experimental}

Thiophene monomer, anhydrous iron (III) chloride $\left(\mathrm{FeCl}_{3}\right)$, polyvinyl acetate (PVA), methanol, and $\mathrm{CoCl}_{2} 6 \mathrm{H}_{2} \mathrm{O}$ from SD 
Fine Chemicals (AR grade) were utilized in the current study. The monomer of thiophene was utilized as received. Composite PTh/PVA prepared according to by chemical oxidative polymerization method. These synthesized PVACo-PTh composite films with various content of Co (II), For these films morphology and the structures were studied by "TEM JEOL JEM-1230"and "scanning electron microscopy" (SEM, JSM-6360LV, Japan) operating at $120 \mathrm{kV}$.The X-ray diffraction patterns of the powders were taken using the "Philips XPERT diffractometer "utilizing $\mathrm{Cu} \mathrm{K} \alpha$ radiation $(\lambda$ $=1.54 \mathrm{~A}^{\circ}$ ). The FTIR - Perkin Elmer make-model RXI Spectroscopy was used to analyze the chemical bonding. UV-Visible measurements were conducted on the "Perkin Elmer make-Lambada" 35 model, as well as absorption spectra, were found by depositing the film PVA-Co-PTh on a glass substrate. The AC conductivity of all the composites with different $\mathrm{Fe}_{2} \mathrm{O}_{3}$ content was studied in the range of frequency 0.2 to $10 \mathrm{MHz}$ by using LCR-Q meter (Wayne Kerr, 4300) analyzer

\section{Preparation}

Polythiophene nanoparticles are synthesized by in situ polymerizations where the thiophene monomer, cobalt chloride is dispersed in the PVA matrix. In one beaker, $3 \mathrm{~g}$ of PVA with MW $=7000$, dissolves fully in $100 \mathrm{ml}$ purified water under continuous agitating. The combination was heated for 1 hour at 90 degrees Celsius and cooled to the temperature of the room. In a cooled combination, $30 \mathrm{ml}$ were combined with $1.0 \mathrm{~g}$ of thiophene (Th) monomer already dissolved in $20 \mathrm{ml}$ of chloroform solution and $2 \mathrm{ml}$ of $\mathrm{FeCl}_{3}$ solution. Five minutes later, the blend was stirred. In a composite mixture, the $0.2 \mathrm{~g}$ cobalt chloride $\left(\mathrm{CoCl}_{2} 6 \mathrm{H}_{2} \mathrm{O}\right)$ was finally utilized for doping and agitated for a further 10 minutes. As mentioned above various amounts of cobalt salt $(x=0.2,0.4,0.6$ and 0.8$)$ were applied, there by producing distinct samples. Thick films were formed using a casting procedure, where the material was placed into a glass Petri dish for the individual samples and allowed to dry 120 hours later on at room temperature, after this period, the films were ready for characterization in appropriate portions.

\section{Results and Discussion $\mathrm{X}$-ray diffraction studies:}

Fig.1. Indicates the pure PVA/PTh composite XRD patterns along with $\mathrm{CoCl}_{2} 6 \mathrm{H}_{2} \mathrm{O}$ salt range doping at 0.0 , $0.2,0.4,0.6$ as well as 0.8 . The PVA/PTh shows large peaks approximately $2 \theta$ values of $15.6^{\circ}$ and $8.9^{\circ}$ showing the amorphous structure and is owing to the scattering on the inter planar spacing from PVA/PTh chains. Rather than large peaks showing amorphous nature $[16,17,18]$, PVA's amorphous nature arises from the strong intermolecular connection of PVA chains via the intermolecular hydrogen bonding in pure PVA-PTh composite film with sulphure thiophene ring of PTh. After complexation with fillers $\mathrm{CoCl}_{2} 6 \mathrm{H}_{2} \mathrm{O}$ salt range from $0.0,0.2,0.4,0.6$ and $0.8 \mathrm{~g}$, the composite samples of PVA-Co-PTh show strong as well as narrow peaks at $38^{\circ} \& 27^{0}$ with extra diffraction peaks at $31.24^{\circ}, 32.3^{\circ}, 34.6^{\circ}, 37.9^{\circ}$ and $38.15^{\circ}$. The appearance of these extra peaks is clear evidence of the $\mathrm{Co}^{2+}$ substitution in PVA/PTh blend and complexation through the oxygen of $-\mathrm{OH}$ groups of PVA via deprotonation
Figure-1.PVA/PTh composite XRD patterns and that doped with filler $\left(0.2,0.4,0.6\right.$, \& $0.8 \mathrm{~g}$ of $\left.\mathrm{CoCl}_{2} 6 \mathrm{H}_{2} \mathrm{O}\right)$. and sulphur of thiophene ring. It is found that the PVA-CoPTh samples have a more crystalline as well as ordered structure than the blend of pure PVA/PTh that keeps the structural stability in the substitution of $\mathrm{Co}^{2+}$ ions in PVA/PTh blend. The XRD peaks observed in PVA/PTh blend are weak \& wide compared with narrow and sharp diffraction peaks in the PVA-Co-PTh samples. The XRD patterns in PVA-Co-PTh show that the diffraction peak intensity rises with the increased concentration of cobalt chloride owing to the semi-crystalline nature of the resulting Co(II) doped PVA/PTh composites. . These findings are also good in line with the morphological alterations in composite PVA-Co-PTh films as found in the following sections in the SEM and TEM analyses [19].

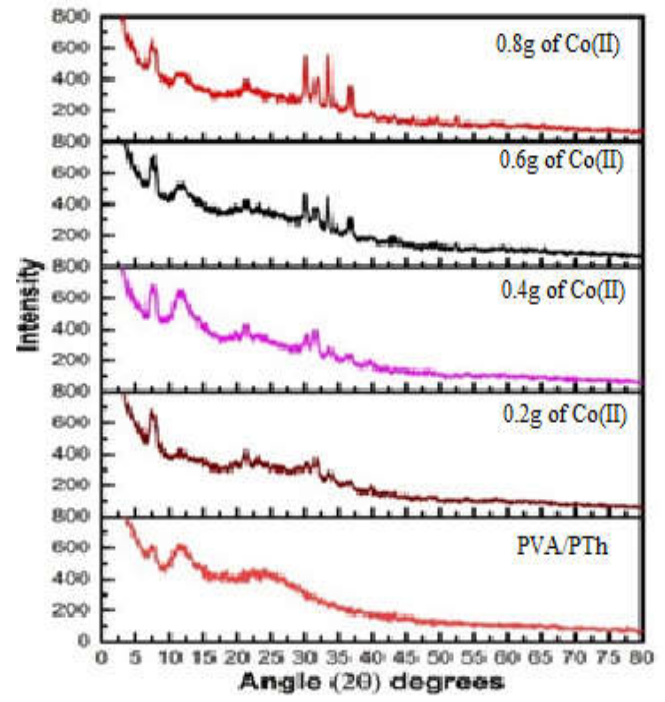

Figure 1: PVA/PTh composite XRD patterns and that doped with filler $\left(0.2,0.4,0.6, \& 0.8 \mathrm{~g}\right.$ of $\left.\mathrm{CoCl}_{2} 6 \mathrm{H}_{2} \mathrm{O}\right)$

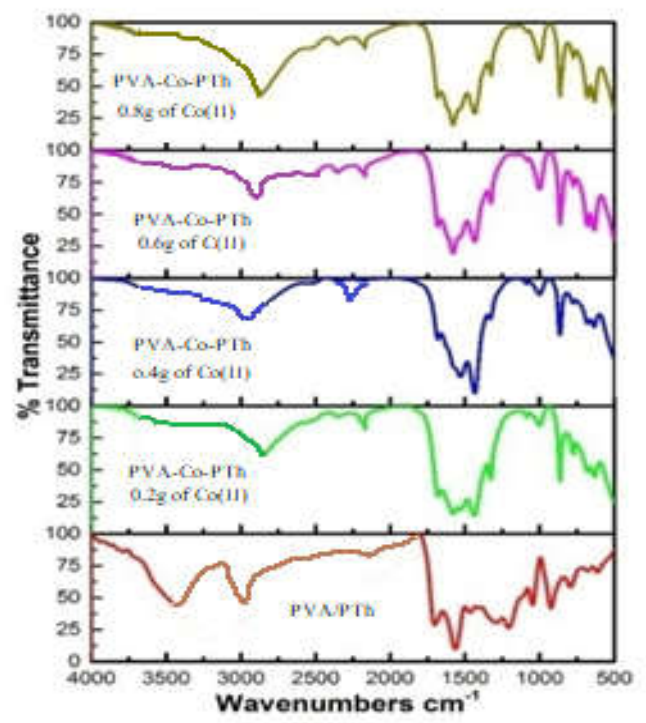

Figure 2: FTIR transmission curves of PVA/PTh and that

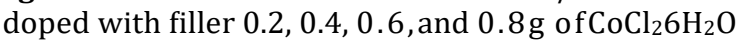

\section{FTIR spectroscopic studies:}

The spectrum from FTIR showed characteristic peak at $3469 \mathrm{~cm}^{-1}$ because of $\mathrm{O}-\mathrm{H}$ stretching frequency of PVA/ PTh blend, but in the IR spectra of PVA-Co-PTh 
composites films this absorption band was absent in all composite films of PVA-Co-PTh due to coordination of $\mathrm{OH}$ group of PVA to $\mathrm{Co}^{2+}$ ion via deprotonation. The main peak for $\mathrm{C}-\mathrm{H}$ stretching vibration occurred at 2838 and 2915 $\mathrm{cm}^{-1}$. The peaks at $1042 \mathrm{~cm}^{-1}$ and $1210 \mathrm{~cm}^{-1}$ were because of $\mathrm{C}-\mathrm{H}$ in-plane deformation \&C-H bending [20]. The peaks on $1405 \mathrm{~cm}^{-1}$ and $1665 \mathrm{~cm}^{-1}$ were givento $\mathrm{C}=\mathrm{C}$ symmetric and asymmetric stretching vibrations of thiophene ring, In PVA-Co-PTh samples all these bands slight shifted to higher frequencies. Polythiophene characteristic peak was obtained at $755 \mathrm{~cm}^{-1}$ (C-S bending) this band also shifted to higher frequencies due to complexation through $\mathrm{S}$ of thiophene ring of PTh in PVA-Co-PTh composite samples. Moreover, the vibration peaks obtained in the range of $550 \mathrm{~cm}^{-1} \& 770-710 \mathrm{~cm}^{-1}$ may be assigned to (M-0) and (C-S), here $\mathrm{M}=\mathrm{Co}^{+2}$ that showed that the doping was polymer matrix complexes Due to the group vibration of $\mathrm{CH}_{2}$ many bands were found at the level $2935-2810 \mathrm{~cm}^{-1}$ [21]. At $1632 \mathrm{~cm}^{-1}$ absorption was given to the thiophene stretching of the $\mathrm{C}=\mathrm{C}$ ring [22]. The characteristic PVA absorption bands which are 1765, 1410, 1130, 920 \& $820 \mathrm{~cm}^{-1}$ were found for each spectrum with certain changes owing to the $\mathrm{Co}^{2+}$ doping formation and PVA$\mathrm{PTh}$ composite. These bands are allocated to $\mathrm{CH}$ rocking of PVA, $\mathrm{C}-\mathrm{O},(\mathrm{CH}-\mathrm{OH}),{ }^{\circ} \mathrm{C}-\mathrm{H}$ band of $\mathrm{CH}_{2}$ group "and $\mathrm{C}=\mathrm{O}$, respectively $[23,24]$. The presence of the band at 1560 $\mathrm{cm}^{-1}$ shows that a tiny conjugated polyene sequence is formed that is probably responsible for doping of $\mathrm{Co}^{2+}$ with PVA--PTh blend.

\section{Morphology study:}

The SEM images of PVA/PTh and the PVA-Co-PTh composites with different weights of fillers 0.2, 0.4, 0.6 and $0.8 \mathrm{~g}$ of $\mathrm{CoCl}_{2} 6 \mathrm{H}_{2} \mathrm{O}$ were shown in Fig.3. The SEM image of PVA/PTh visualizes the presence of an equal ratio of secondary phase (PThs) which was randomly distributed and get adhered to on PVA matrix [25,26]. PVA-Co-PTh Sample surface morphology is significantly altered by increasing the concentration of Co (II). Surface morphology exhibits globular structures for the PVA-Co-PTh sample with the lowest CO(II) concentrations. The samples' morphology varies significantly from that of PVA/PTh, as the concentration rises to the medium. Doping Co(II) shows that the particles appear to merge into the adjacent particles, generating a large-scale structure that can be found in the SEM images of the PVA-Co-PTh samples on a medium level of doping Co(II). Increasing the concentration of Co (II) doping to the greatest level, higher flakes are seen that show homogeneity in Co(II) distribution within the PVA/PTh matrix. This form of more ordered structure helps to organize electricity conductive networks inside the PVA/PTh chains, which lead to increased electron transfer between the flacks and hence contribute to high levels of electrical conductivity. The SEM analysis indicates that with the rise in $\operatorname{Co}(\mathrm{II})$ concentration, the samples are structurally ordered. Based on the XRD studies, the production of such ordered structures validates previous findings.

Fig.4 shows PVA/PTh composite TEM images which are processed with cobalt fillers. For pure PVA/PTh it may be shown that composite morphology shows nanospherical particle agglomeration such as shaped in the 50-60 $\mathrm{nm}$ range. The size of particles reduced to $4 \mathrm{~nm}$ when fillers are added to limit the growth of PVA/PTh composite polymerization process by complexity with the filler ratios $\mathrm{x}=0.2,0.4$ as well as $0.6 \mathrm{~g}$ Figure. 4. 0.2 and $0.6 \mathrm{~g}$. [27]. The nanoparticles tend to create a higher agglomeration, with a further increase in filler $(0.8 \mathrm{~g})$.
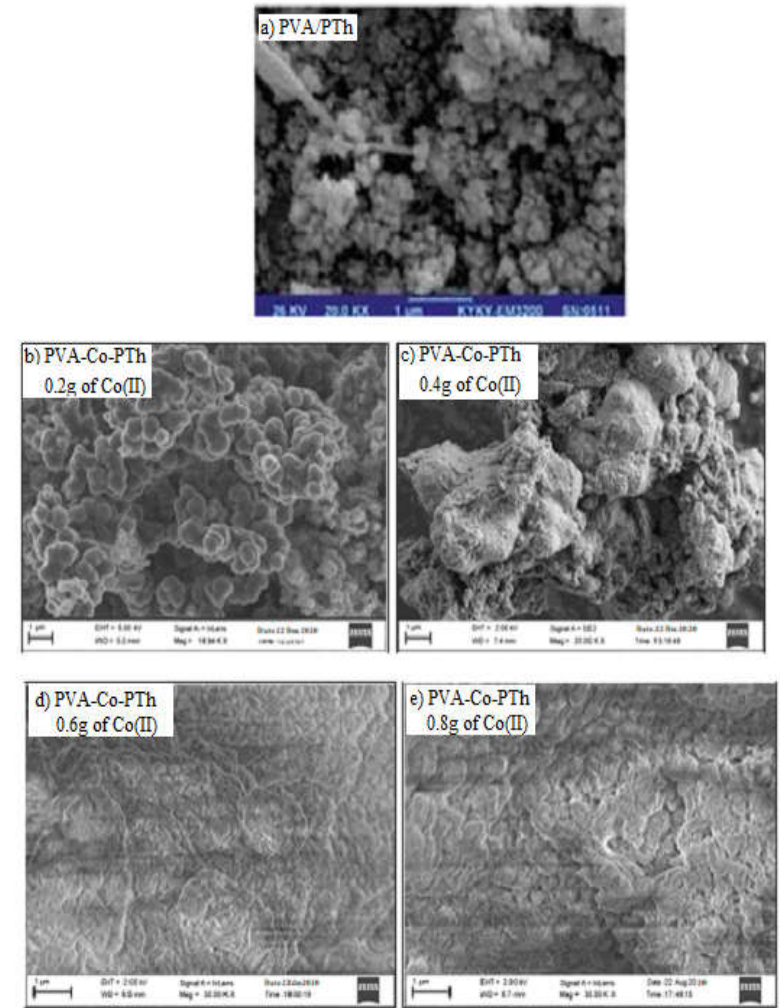

Figure 3: SEM images of PVA/PTh and that doped with filler a) PVA/PTh b)0.2, c) 0.4, d) 0.6 and e) $0.8 \mathrm{~g}$ of $\mathrm{CoCl} 26 \mathrm{H} 20$ )

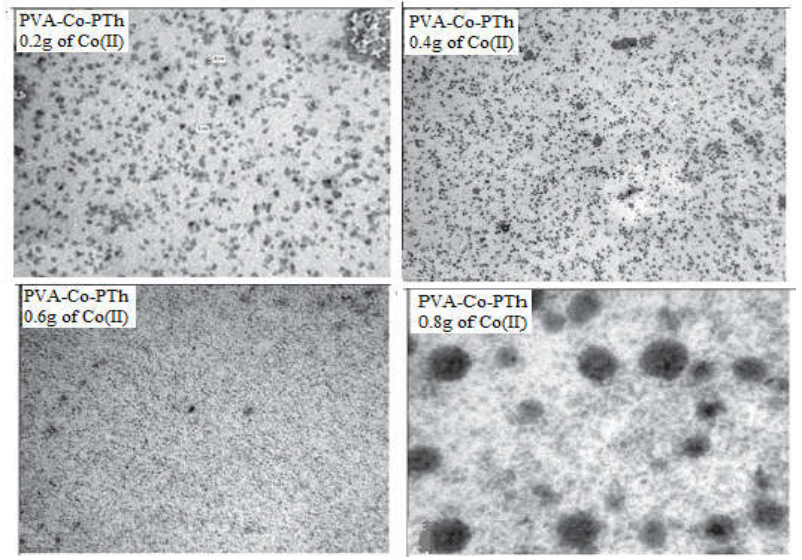

Figure 4: TEM images of PVA/PTh and that doped with fillers 0.2 , $0.4,0.6$ and $0.8 \mathrm{~g}$ of $\mathrm{CoCl} 26 \mathrm{H} 2 \mathrm{O}$

UV-Visible absorption studies

Figure 5 indicates the UV-VIS spectrum of the examined sample, the spectrum of pure PVA/TH, and that doped at various concentrations of cobalt chloride salt $(\mathrm{x}=0.2$, $0.4,0.6$ as well as $0.8 \mathrm{~g}$ ). The optical absorption of the produced films rises with rising the $x$ value of Co$\mathrm{Cl}_{2} 6 \mathrm{H}_{2} \mathrm{O}$ in UV (200-400nm) and VIS(500-700nm) regions and the $\mathrm{PVA} / \mathrm{PTh}$ with one spectral band on340 $\mathrm{nm}$ [28]. With increased $\mathrm{CoCl}_{2} 6 \mathrm{H}_{2} \mathrm{O}$ contents the intensity of the bands rises which is evidence for the integration of $\mathrm{Co}^{2+}$ into PVA/PTh matrix when its positions are slightly changed to a greater wavelength. The octahedral structure around the Co(II) ion is characterized by two absorption bands of about 550 and $625 \mathrm{~nm}$. The appearance of $\mathrm{Co}^{2+}$ ions fully as six 
coordinated. The impact of Jahn-Teller may be linked to their asymmetry. This distortion was observed progressively decreased by increasing the $\mathrm{CoCl}_{2} 6 \mathrm{H}_{2} \mathrm{O}$ concentration, indicating a tendency to local order via cobalt chloride additions in the amorphous polymer structure [29].

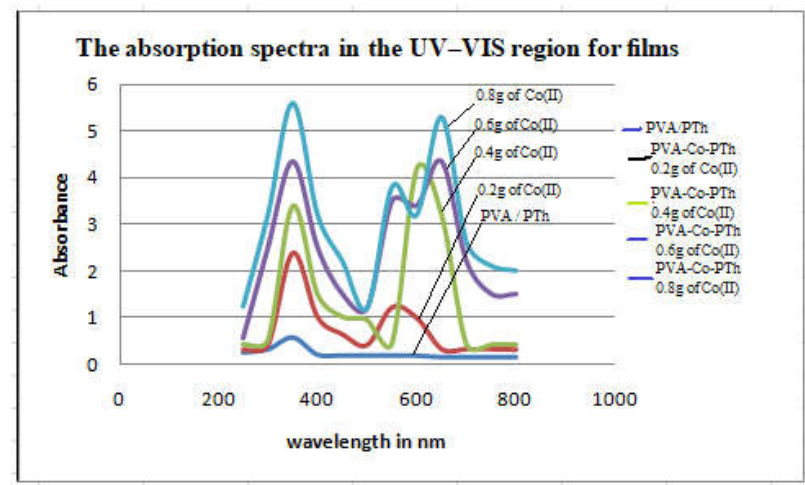

Figure 5: The absorption spectra in the UV-VIS region for films of PVA/PTh and that doped with 0.2, 0.4, 0.6 and $0.8 \mathrm{~g}$ of $\mathrm{CoCl} 26 \mathrm{H} 2 \mathrm{O}$

\section{Electrical Conductivity:}

Conductivity variation with temperature for the various composites PVA-Co-PTh is indicated in Fig.6. Conductivity increased by increasing temperature, which shows that semiconducting nature, these results agree with the findings reported by other comparable systems[30].

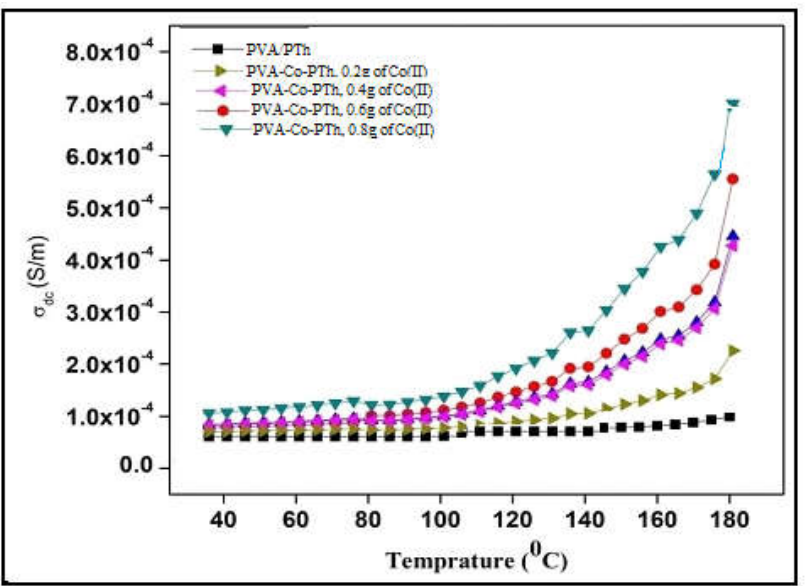

Figure 6: Temperature dependence of electrical conductivity of composites, PVA-Co-PTh. and that doped with 0.2, 0.4, 0.6, and $0.8 \mathrm{~g}$ of $\mathrm{CoCl} 26 \mathrm{H} 2 \mathrm{O}$

The measured room temperature conductivity for PVA/PTh, and that doped with $(0.2,0.4,0.6$, and $0.8 \mathrm{~g}$ of $\mathrm{CoCl}_{2} 6 \mathrm{H}_{2} \mathrm{O}$, PVA-Co-PTh. Composites are $0.56 \times 10^{-4}$ $(\Omega \mathrm{m})^{-1}, 0.66 \times 10^{-4}(\Omega \mathrm{m})^{-1}, 0.78 \times 10^{-4}(\Omega \mathrm{m})^{-1}, 0.89 \times 10^{-4}$ $(\Omega \mathrm{m})^{-1}$ as well as $1.08 \times 10^{-4}(\Omega \mathrm{m})^{-1}$. These values are 2 orders of magnitude less than the reported values for individual pure PVA and PTh. This indicates that conductivity increases with the integration of $\mathrm{Co}^{2+}$ in PVA-PTh. The increase in conductivity with an increase in $\mathrm{Co}(\mathrm{II})$ concentration up to $0.8 \mathrm{~g}$ of $\mathrm{CoCl}_{2} 6 \mathrm{H}_{2} \mathrm{O}$ has been observed in PVA-Co-PTh composites [31]. The conducting data with temperature was matched to conductivity expression originated under Motts small polaron hopping model [32]. Under this model, conductivity is provided in the non-adiabatic region

$$
\sigma=\sigma_{0} / \mathrm{T} \exp \left\{\mathrm{E}_{\mathrm{a}} / \mathrm{KBT}\right\}
$$

Where $\mathrm{E}_{\mathrm{a}}$ indicates small polaron hopping activation energy and $]_{0}$ signifies pre-exponential factor. The plots of $\ln (\sigma \mathrm{T})$ vs $(1 / \mathrm{T})$ were produced for all the composites according to equation (1). The least-square linear lines were fit to high-temperature data in the region in which the data was extracted linear and slopes. Ea (activation energy) of the relevant sample was determined using the slope of each line.

The variation in activation energy $\left(E_{a}\right)$ as well as conductivity $(\sigma)$ at $300 \mathrm{~K}$ as functions of wt $\%$ of $\mathrm{CoCl}_{2} \cdot 6 \mathrm{H}_{2} \mathrm{O}$. It can be noted that $\mathrm{E}_{\mathrm{a}}$ decreased and conductivity increased with the rise of wt $\%$ of $\mathrm{CoCl}_{2} .6 \mathrm{H}_{2} \mathrm{O}$ content. The fact that the leading process is mused very easily by the appearance of Co(II) grains in between PVAPTh grains could be causing an increase in conductivity by increasing the $\mathrm{Co}(\mathrm{II})$ content.

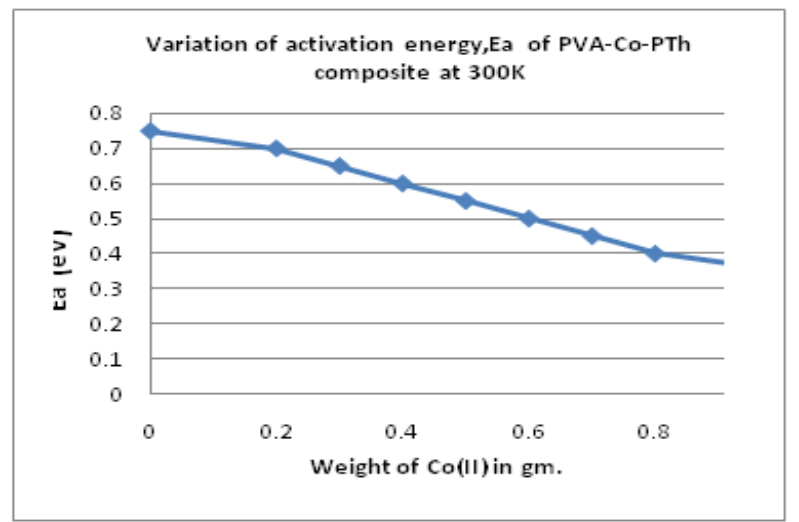

Figure 7: Variation of activation energy, Ea at $300 \mathrm{~K}$ as a function of weight in gms of $\mathrm{CoCl} 2.6 \mathrm{H} 2 \mathrm{O}$ in PVA-Co-PTh composites.

\section{Dielectric Properties:}

The dielectric property of the material can be dependent on frequency. In this study, the dielectric property of the sample is evaluated by estimating different parameters such as capacitance $\mathrm{C}_{\mathrm{p}}$ and RP (Relative permittivity) \& LP (loss factor) dielectric constant of the films at room temperature [33]. The dielectric behavior $\left(\varepsilon^{\prime}\right)$ as the variation of frequency for PVA-Co-PTh composites with varying $\operatorname{Co}(\mathrm{II})$ content. It may be observed that the "dielectric constant" $\varepsilon^{\prime}$ up to $4 \times 10^{5} \mathrm{~Hz}$ for all the composites is constant. Later the dielectric constant tends to increase with the increment infrequency as well as with enhancement in Co(II) composition. Incorporation of Co(II) eventuated in a significant increment in the dielectric constant of the sample. The variation in the dielectric constant is generally specified to the concentration of $\mathrm{Co}^{2+}$ ions within the composites. Further, the increment in the dielectric constant can also be specified to increase in AC conductivity of the composites. This indicates that the better the dielectric constant, the higher is the capability of composites to store electric energy [34].

\section{Conclusions}

Polyvinyl alcohol-Co-polythiophene (PVA-Co-PTh) composite polymer films have been produced using a chemical polymerization. The analysis of X-ray indicated an amorphous filmsstructure PVA/PPY complexation with $\mathrm{CoCl}_{2} 6 \mathrm{H}_{2} \mathrm{O}$ as filler. After complexation with fillers $\mathrm{CoCl}_{2} 6 \mathrm{H}_{2} \mathrm{O}$ salt range from $0.0,0.2,0.4,0.6$ as well as 
0.8g, the PVA-Co-PTh composite samples show strong \& narrow peaks on $27^{\circ}$ and $38^{\circ}$ with extra diffraction peaks on $31.24^{0}, 32.3^{\circ}, 34.6^{\circ}, 37.9^{\circ}$ and $38.15^{\circ}$. The appearance of these extra peaks is clear evidence of the $\mathrm{Co}^{2+}$ substitution in PVA/PTh blend and complexation through the oxygen of $-\mathrm{OH}$ groups of PVA via deprotonation and sulphur of thiophene ring. The FTIR spectra indicated a characteristic peak at $3469 \mathrm{~cm}^{-1}$ owing to $\mathrm{O}-\mathrm{H}$ stretching frequency of PVA/ PTh blend, but in the IR spectra of PVA-Co-PTh composites films this absorption band was absent in all composite films of PVA-Co-PTh due to coordination of $\mathrm{OH}$ group of PVA to $\mathrm{Co}^{2+}$ ion via deprotonation. The SEM analysis demonstrates that with the rise in Co (II) content, the samples are structurally more ordered. The development of these ordered structures is based on the XRD investigations, which validate prior results. The TEM images showed that the size of particle declined with filler complexation at $(0.0$ to $0.6 \mathrm{~g})$ in which excess filler addition inhibited the growth of PVA/PTh polymerization and strong agglomeration of the remaining specimen $(0.8 \mathrm{~g}$ of Co (II)) with high content filler owing to extremely fine nanoparticles formations were seen. The UV-VIS spectrum shows the metal-polymer complexes formation. Furthermore, the optical properties have indicated that the pure PVA/PPTh has a single optical absorption edge, whereas the PVA/PTh containing $\mathrm{CoCl}_{2} 6 \mathrm{H}_{2} \mathrm{O}$ has three edges of optical absorption. The increase in conductivity with an increase in $\mathrm{Co}(\mathrm{II})$ concentration up to $0.8 \mathrm{~g}$ of $\mathrm{CoCl}_{2} 6 \mathrm{H}_{2} \mathrm{O}$ has been observed in PVA-Co-PTh composites. It may be seen that $\mathrm{E}_{\mathrm{a}}$ (activation energy) declined and conductivity raised with the rise of $\mathrm{wt} \%$ of $\mathrm{CoCl}_{2} 6 \mathrm{H}_{2} \mathrm{O}$ content. The dielectric constant tends to increase with the increment in frequency as well as with enhancement in Co(II) composition.

\section{Acknowledgments:}

We are thankful to Poojya Dr.Sharanbasvappa Appa, President "Sharanbasveshwar Vidya vardhak Sangha, Kalaburagi", Dr. Anilkumar Bidve, Registrar, and Registrar(Eval) Dr. Lingaraj Shastry, Dean, Dr. Basavaraj Mathapathi, and Dr. Laxmi Patil Sharnbasva University Kalaburagi, Karnataka, for their constant encouragement and support during the process of performing this work.

\section{References}

1. Allhoff Fritz, Lin Patrick, Moore Daniel, "What is nanotechnology and why does it matter", Journal of John Wiley and Sons, 2010, 3.

2. Fromageau J. Brusseau E, Vray D., Gimenez G, Delachartre P, Characterization of PVA cryogel for intravascular ultrasound elasticity imaging, IEEE, 2003, 50, 10. DOI : $10.1109 /$ TUFFC.2003.1244748

3. Jonathan Swanston, "Thiophene" in Ullmann's Encyclopedia of Industrial Chemistry Wiley V C H, Weinheim, 2006,

4. J Suand N Kuramoto, Synthesis of processable polyaniline complexed with anionic surfactant and its conducting blends in aqueous and organic system, Synthetic Metals, 2000, 108, 2,.121-12. DOI : 10.1016/S0379-6779(99)00185-X

5. P P Sengupta, S Barik and B Adhikari, Polyaniline as a GasSensor Material "Materials and Manufacturing Processes, 2007,21,3,263-270. DOI : 10.1080/10426910500464602

6. S Dogan, U Akbulut, T Yalcin, S Suzer, and L Toppare, Conducting polymers of aniline II. A composite as a gas sensor, Synthetic Metals, 1993, 60,1, 27-30. DOI : 10.1016/0379-6779(93)91179-6

7. J Wang, S Chen, and M S Lin, Use of different electro polymerization conditions for controlling the size-exclusion selectivity at polyaniline, polypyrrole and polyphenol films,
Journal of Electro analytical Chemistry, 1989, 273,.1-2,231242. DOI :10.1016/0022-0728(89)87016-0

8. Riul Jr A M, G Soto, S V Mello, S.Bone, D M Taylor and L. H C Mattoso, An electronic tongue using polypyrrole and polyaniline, Synthetic Metals, 2003, 132,2,109-116. DOI: 10.1016/S0379-6779(02)00107-8.

9. Paoli M A D, Waltman R .J., Diaz A F., Bargon J., Conductive composites from poly (vinyl chloride) and polypyrrole J. Chem. Soc., Chem. Commu.,1984, 15, 1015-1016.

10. Lindsey S E, Street G B., Conductive composites from poly(vinyl alcohol) and polypyrrole Synth. Metal.,1984, 10,1,67-69. DOI : 10.1016/0379-6779(84)90080-8.

11. Niwa $O$, Tamamura $T$ Preparation of an electrically conducting polymer by the electrolytic polymerization of $N$-vinylcarbazole Chem. Soc., Chem. Commun., 1984, 470, 817-818.

12. Otero T F, M. Bengoechea In situ absorption-reflection study of polypyrrole composites switching stability J. Electro chemical Acta.,1996, 412, 6, 109-11. DOI: 10.1016/0013-4686(95)00506-4

13. F Sharaf, M A Khaled, A A Abdel-Rahman, A F Basha, Optical absorption in gamma irradiated poly(vinyl alcohol) $\mathrm{CoCl}_{2}$ composites,1991,1,4,206 DOI : 10.1002/actp.1991.010421206

14. Barakat N., El-Hennawi H A, El-Ocker M., Shraf F. Effect of gamma irradiation on the refractive indices, birefringence and optical absorption of blue Cashmeline fibre J. Phys. D: Appl. Phys.,1989,22, 786.

15. Noguchi $H$, Joda $H$, Yamaura $K$, Matsuzawa $S$. , Formation of poly(vinyl alcohol)-iodine complex in aqueous solution: a SEM study of the freeze-dried substances, Polym. Int., 1998, 47, 428. DOI : 10.1002/(SICI)10970126(199812)47:4<428::AID-PI56>3.0.CO;2-W.

16. El-Tantawy F, Abdelkader K M, Kane Ko F, Sung Y K. Physical properties of CdS-poly (vinyl alcohol) nanoconducting composite synthesized by organosol techniques and novel application potential, Eur. Polym. J., 2004, 40, 415. DOI : 10.1016/j.eurpolymj.2003.10.013

17. Huang S J, Lee H K., Kang, W H. Proton Conducting Behavior of a Novel Composite Based on Phosphosilicate/Poly (Vinyl Alcohol), J. Korean. Ceram. Soc.,2005. 42,77. DOI : 10.4191/KCERS.2005.42.2.077

18. Bhargav P B, Mohan V M., Sharma A K., Narasimha Rao V V R, Structural, Electrical and Optical Characterization of Pure and Doped Poly (Vinyl Alcohol) (PVA) Polymer Electrolyte Films., Int. J. Polym. Mater., 2007, 56, 579. DOI : 10.1080/00914030600972790

19. S A Waghuley, S M Yenorkar, S S Yawale and S P Yawale, Application of chemically synthesized conducting polymerpolypyrrole as a carbon dioxide gas sensor, Sens. Actuators B,1984, 128, 366. doi.org/10.1016/j.snb.2007.06.023

20. Ege S N, Organic Chemistry. The University of Michigan, AnnArbor, pp. 361. (1989).

21. Sweeting O. J. The Science and Technology of Polymer Films. Interscience Publishers, Newyork. 1968.

22. Mingzheng Ge, Chunyan Cao, Jianying Huang, Shuhui Li, Zhong Chen, KeQin Zhang, S. S. Al-Deyab and Yuekun Lai, A Review of One-dimensional TiO2 Nanostructured Materials for Environmental and Energy Applications„,2012 1-26. DOI : 10.1039/x0xx00000x.

23. Rajendran S, Sivakumar M, Subadevi R, Investigations on the effect of various plasticizers in PVA-PMMA solid polymer blend electrolytes, Mater. Lett., 2004, 58, 641. DOI : 10.1016/S0167-577X(03)00585-8

24. Chakraborty M, Mukherjee D C, Mandal B M., Interpenetrating polymer network composites of polypyrrole and poly(vinyl acetate), Synth. Metals., 1999, 98, 193. DOI : 10.1016/S0379-6779(98)00184-2

25. Horák Daniel, Bohuslav Rittich and Alena Španová, Effect of reaction parameters on properties of dispersionpolymerized hydrophilic microspheres as supports for immobilization of proteins, Progress in Colloid and Polymer Science, 2004, 124, 77-81. DOI : 10.1007/978-3540-36474-0_16.

26. Woong K., Y. L. Jae and L. Hoosung., Synth. Met., 78, Solution-cast polypyrrole film: the electrical and thermal 
properties,1996,78,177-180. DOI : 10.1016/03796779(96) $80120-2$

27. Jianyong $\mathrm{O}$ and L. Yongfang, Effect of electrolyte solvent on the conductivity and structure of as-prepared polypyrrole films, Polymer,1997,38,1971-1976. DOI : 10.1016/S00323861(96)00749-5.

28. Abdelazeez M, Abdelrazek E M, Effect of dopant mixture on structural, optical and electron spin resonance properties of polyvinyl alcohol, Physica B. 2007,390, 1-2,1-9, DOI : 10.1016/j.physb.2006.07.067.

29. El-Shahawy M A Spectral changes of co-doped PVA films in relation to their structures, Polym. Bull. 1993, 31,199. DOI : $10.1007 /$ BF00329966

30. Zidan H M, Tawansi A, Abu-Elnader M, Miscibility, optical and dielectric properties of UV-irradiated poly(vinylacetate)/poly(methylmethacrylate) blends, $\begin{array}{lll}\text { Physica } & \text { B. } 2003,339, \quad 78 . & \text { DOI : }\end{array}$ 10.1016/j.physb.2003.08.054
31. G M Elkomy , S M. Mousa , H Abo Mostafa, Structural and optical properties of pure PVA/PPY and cobalt chloride doped PVA/PPY films, Arabian Journal of Chemistry.2016, 9,2, S1786-S1792. DOI : 10.1016/j.arabjc.2012.04.037

32. Murri R, Schiavulli L, Pinto N, Ligonzo T, Urbach tail in amorphous gallium arsenide films, J. Non-Cryst. Solids.,1992,139,60.DOI : 10.1016/S0022-3093(05)80805-1.

33. P Chitra, A Muthusamy, R Jayaprakash, Structural, magnetic and dielectric properties of polyaniline $/ \mathrm{MnCoFe}_{2} \mathrm{O}_{4}$ nanocomposites, J. Magn. Magn. Mater., 2015, 396. DOI : $10.1016 /$ j.jmmm.2015.08.042

34. L Yang J. Qiu H Ji, K. Zhu J. Wang, Enhanced dielectric and ferroelectric properties induced by $\mathrm{TiO}_{2} @ M W C N T s$ nanoparticles in flexible poly(vinylidene fluoride) composites Composites: Part A, 2014, 65,125-134. DOI : 10.1016/j.compositesa.2014.06.006. 